\title{
Analisis Finansial Usahatani Cabai Keriting (Capsicum annum L) di Desa Lawalutolus, Kecamatan Tasifeto Barat, Kabupaten Belu. ( Studi Kasus pada Kelompok Wanita Tani Tunas Muda)
}

\author{
Serfandus Bria ${ }^{\mathrm{a}}$, Adeline Norawati Hutapea ${ }^{\mathrm{b}}$, dan Umbu Joka ${ }^{\mathrm{c}}$ \\ ${ }^{a}$ Fakultas Pertanian, Universitas Timor, Kefamenanu, TTU - NTT, Indonesia.Email: serfandusbria@gmail.com \\ ${ }^{b}$ Fakultas Pertanian, Universitas Timor, Kefamenanu, TTU - NTT, Indonesia.Email: adelinenorawati@gmail.com \\ ${ }^{c}$ Fakultas Pertanian, Universitas Timor, Kefamenanu, TTU - NTT, Indonesia.Email: umbujoka@unimor.ac.id
}

\section{Article Info}

Article history:

Received 2 Maret 2020

Received in revised form 15 Maret 2020

Accepted 7 April 2020

https://doi.org/10.32938/ag.v5i2.1026

Keywords:

Cabai Merah Keriting

Kelayakan Finansial

\section{Abstrak}

Penelitian ini bertujuan untuk mengetahui kelayakan finan ial usahatani cabai keriting di Kelompok Wanita Tani Tunas Muda dengan luas lahan 30 are. Metode penentuan sampel dalam penelitian ini yakni Teknik purpose sampling yang artinya ketua, bendahara dan sekertaris Kelompok Wanita Tunas Muda. analisis data yang digunakan diantaranya analisis deskriptif kualitatif untuk mengetahui gambaran umum usahatani cabai keriting sedangkan untuk mengetahui analisis kelayakan finansial menggunakan analisis deskriptif kuantitatif diantaranya R/C Rasio, NPV, IRR, Break Event Point, dan Payback Periode. Hasil penelitian menunjukan bahwa Kelompok Wanita Tani Tunas Muda dalam melakukan usahatani cabai keriting dengan luas lahan 30 are memiliki biaya usahatani $\mathrm{Rp} 4.584 .000$, sedangkan total penerimaan sebesar Rp 14.014.000. Hasil analisis kelayakan finansial menunjukan bahwa : 1). Nilai R/C Rasio sebesar 3,06. 2). NPV dengan tingkat $4,25 \%$ sebesar Rp 7.187.284; 3). IRR sebesar Rp 36\% . 4). BEP, titik impas untuk usahatani cabai keriting pada volume produksi $213 \mathrm{Kg}$, pada penerimaan dan biaya sebesar Rp 4.584.000. 5). Payback Periode sesesar 3,64. Sehingga dapat di katakan bahwa analisis Finansial Usahatani Cabai Keriting di Desa Lawalutolus Kecamatan Tasifeto Barat Kabupaten Belu Layak untuk dilaksanakan.

\section{Pendahuluan}

Cabai adalah sayuran sekaligus rempah dapur yang hampir selalu hadir pada hidangan yang kita santap sehari-hari. Cabai dalam masyarakat biasanya digunakan sebagai bumbu, sambal dan dimakan bersama gorengan. Proses pemasakan pada cabai juga berbeda-beda seperti dengan cara digoreng dan direbus. Proses pemasakan tersebut akan berdampak pada kandungan zat gizi pada cabai khususnya vitamin. Nilai gizi dalam cabai Vitamin yang terkandung dalam cabai dan berguna bagi tubuh salah satunya adalah vitamin $\mathrm{C}$ dan provitamin A ( $\beta$-karoten). menurut Cahyono (2003), kandungan vitamin C dalam 100 gram cabai adalah $70 \mathrm{mg}$.

Produksi cabai di tingkat nasional setiap tahun terus meningkat di dukung oleh banyak usaha-usaha di bidang industri dan komsumsi masyarakat yang terus meningkat. Produksi cabai di tingkat Nasional pada tahun 2015 sebesar 1.915.016 Ton dan pada tahun 2016 sebesar 1.961.598 Ton (meningkat sebesar 2 persen) dan pada tahun 2017 sebesar 2.359.441 ton (naik 20 persen) BPS (2019).

Luas wilayah daratan NTT adalah seluas $47.931,54 \mathrm{~km} 2$. Produksi caba untuk tingkat Provinsi NTT meningkat setiap tahunnya, pada tahun 2015 sebanyak 37.236 Ton, tahun 2016 meningkat 52,4 persen sebesar 56.769 Ton dan pada 2017 meningkat lagi sebesar 35,2 persen atau 76.758 Ton. Terdapat 21 kabupaten di Provinsi NTT yang mengusahakan cabai keriting dan, salah satunya Kabupaten Belu.

Kabupaten Belu merupakan salah satu wilayah perbatasan yang juga menjadi tujuan baru sentra produksi cabai di Indonesia timur, hal ini dicanangkan pemerintah guna mengendalikan harga komoditas ini yang fluktuatif karena beberapa tahun sebelumnya sangat bergantung pada pasokan dari luar Pulau Timor seperti dari kab. Rote Ndao. Cabai merupakan salah komoditas yang diusahakan di Kabupaten Belu. Untuk produksi cabai pada tahun 2016 sebanyak 472 Ton dan pada tahun 2017 sebanyak 442,9 Ton atau megalami penurunan sebesr 6,5 persen. Rata-rata cabai yang diusahakan di Kabupaten Belu adalah cabai merah besar, cabai keriting dan cabai rawit (BPS Kab. Belu, 2019)

Kecamatan Tasifeto Barat merupakan suatu wilayah yang terletak di Kabupaten Belu dan merupakan kecamatan dengan wilayah terluas yaitu sebesa $224,19 \mathrm{~km}^{2}$ atau $(17,46 \%)$. Wilayah administrasi terbagi dalam 8 Desa dan 62 dusun atau lingkungan. Luas lahan tersebut digunakan masyarakat sebagai pemukiman, peternakan, pertanian dan perhutanan. Ada beberapa Desa yang mengusahakan cabai keriting di antaranya Desa Lawalutolus, Desa Rinbesiha dan Desa Naitimu. Namun yang mempunyai potensi untuk mengusahakan cabai keriting setiap tahunnya adalah Desa Lawalutolus. Karena Desa Naitimu dan Desa Rinbesihat lebih dominan pada produksi tanaman pangan.

Peneliti memilih Desa Lawalutolus karena merupakan salah satu desa yang mempunyai salah satu kelompok tani yaitu Kelompok Wanita Tani yang selanjutnya di singkat KWT Tunas Muda yang melakukan usahatani caba keriting setiap tahunnya, berbeda dengan KWT di Desa lainnya yang fokus pada usaha tenun, dan sayuran daun. KWT Tunas Muda di bentuk pada tahun 2005 dengan luas lahan 30 are dan produksi cabai keriting untuk tiga tahun terakhir yaitu pada tahun 2015 sebanyak $651 \mathrm{~kg} /$ musim tanam, tahun 2016 meningka sebesar 26,1 persen sebanyak $821 \mathrm{~kg} /$ musim tanam dan menurun sebesar 4 persen pada tahun 2017 sebanyak $780 \mathrm{~kg} /$ musim tanam sehingga produksi cabai keriting di KWT Tunas Muda berfluktuasi. Pemasaran hasil cabai keriting yang dilakukan oleh KWT Tunas Muda yaitu hasil produksi cabai dijual ke pasar yaitu pasar Atambua dan Kupang. Untuk penjualan cabai keriting ke Atambua, langsung ke pedagang pengecer, sementara untuk ke Kupang dijual ke pedagang pengumpul. KWT Tunas Muda juga memiliki manajemen yang baik, meskipun masih sederhana dan selalu melakukan evaluasi-evaluasi, dimana dalam mengelola keuangan mereka masih menggunakan perhitungan sederhana. Sehingga harus adanya pengembangan usahatani cabai keriting dan perlu dikaji jika investor menanamkan modalnya di KWT Tunas Muda apakah menguntungkan atau tidak menguntungkan.

\section{Metode}

Penelitian ini bertempat di Desa Lawalutolus, Kecamatan Tasifeto Barat Kabupaten Belu dari bulan Januari sampai Agustus tahun 2019. Obyek penelitian adalah Kolompok Wanita Tani (KWT) Tunas Muda sebagai petan pengelola usahatani cabai keriting pada musim tanam tahun 2019 di Desa Lawalutolus, Kecamatan Tasifeto Barat Kabupaten Belu dari bulan Januari sampai Agustus tahun 2019

Data-data dalam penelitian ini diperoleh melalui proses survey dan wawancara secara terstruktur dengan bantuan kuesioner. Penentuan Populasi dalam penelitian ini adalah seluruh anggota KWT Tunas Muda, sedangkan sampel dalam penelitian ini adalah Ketua, Sekretaris Kelolompok tani KWT Tunas Muda.

Metode analisis data menggunakan kombinasi dari: Metode Deskriptif Kualitatif Metode deskriptif kualitatif dalam penelitian ini adalah untuk mengetahui gambaran umum usahatani cabai keriting di KWT Tunas Muda Metode Deskkiptif kuantitatif (Analisis Kelayakan Finansial). Untuk mengetahu Tujuan kedua maka di perlukan analisis kelayakan finansial yang merupakan kriteria penilaian usahatani cabai keriting layak un tuk di laksanakan atau tidak layak untuk di laksanakan. untuk menghitung kelayakan finansial dapat di pakai beberapa alat analisis, seperti

1. $R / C$ Rasio (Return/ Cost Rasio) merupakan alat analisis yang di gunakan untuk menghitung pendapatan dan biaya dalam usahatani. Sehingga di ketahui apakah usahatani cabai keriting menguntungkan atau rugi.

$\mathrm{R} / \mathrm{C}$ Ratio $=\mathrm{TR}$

$$
\mathrm{TC}
$$

Kriteria :

$\mathrm{R} / \mathrm{C} \geq 1 \quad$ : menguntungkan

$\mathrm{R} / \mathrm{C}<1 \quad$ : tidak menguntungkan.

2. $\quad N P V$ (Net Present Value) NPV adalah selisih antara Present Value dari arus Benefit dikurangi Present Value PV dari arus biaya (Soekartawi et al. 2011). Persamaan secara matematis sebagai berikut:

$$
N P V=\sum_{t=1}^{n} \frac{\mathrm{Bt}-\mathrm{CT}}{(1+\mathrm{i})^{\mathrm{t}}}
$$

Keterangan:

$\mathrm{Bt} \quad=$ Benefit pada panen ke-t (satu musim tanam)

$\mathrm{Ct} \quad=$ Biaya pada musim tanam ke- $\mathrm{t}$

$\mathrm{t} \quad=$ lamanya waktu investasi

i $\quad=$ tingkat bunga

NPV $>0$ atau positif maka proyek menguntungkan, sebaliknya bila NPV $<0$ (negatif) maka proyek/usahatani tersebut tidak layak untuk diusahakan. Present Value (nilai sekarang) : berapa nilai uang saat ini untuk nilai tertentu di masa yang akan datang.

\section{Internal Rate Return}

IRR adalah nilai discountu rate (I) yang membuat NPV suatu proyek sama dengan nol atau dengan perkataan lain IRR menunjukkan present value (benefit) sama dengan present value (cost) Digunakan untuk mencari tingkat bunga yang menyamakan Bt pada nilai sekarang dengan $\mathrm{Ct}$ pada nilai sekarang di masa-masa mendatang yang di nyatakan dalam Persen. Penggunaan Investasi akan layak jika diperoleh IRR yang persentasenya lebih besar dari tingkat suku bunga bank yang ditentukan, karena proyek berada dalam keadaan yang menguntungkan, demikian juga sebaliknya jika IRR lebih kesil dari tingkat suku bunga bank yang ditentukan, berarti proyek merugi dan tidak layak untuk dilaksanakan. 


$$
I R R=i_{1}+\frac{N P V_{1}}{\left(N P V_{1}-N P V_{2}\right)}\left(i_{1}-i_{2}\right)
$$

Keterangan:

$\mathrm{NPV}_{1}$

modal sebesar $\mathrm{i}_{1}$ persen

$\mathrm{NPV}_{2}=$ Perhitungan NPV negatif mendekati nol dengan bunga modal sebesar i2 persen

$\mathrm{i}_{1} \quad=\quad$ Discount factor $(\mathrm{DF})$ pertama, tingkat bunga yang menghasilkan NPV positif

$\mathrm{i}_{2}=$ Discount factor (DF) kedua, tingkat bunga yang menghasilkan NPV negatif.

\section{Break Event Point}

Analisis BEP bertujuan untuk mengetahui besarnya pendapatan pada saa titik balik modal, yaitu yang menunjukkan bahwa suatu proyek/usahatani tidak dapat mendapatkan keuntungan tetapi juga tidak mengalami kerugian. Menurut Riyanto (1997), BEP dapat dihitung dengan dua cara yaitu:

a. Atas dasar penjualan dalam unit

$$
B E P=\frac{F C}{P-V C}
$$

Keterangan:

$\mathrm{FC} \quad=$ Biaya tetap

$\mathrm{P} \quad=$ Harga jual per unit

$\mathrm{VC}=$ Biaya variabel per unit

b. Atas dasar penjualan dalam rupiah.

$$
\begin{aligned}
\qquad E P P & =\frac{F C}{1-\frac{V C}{p}} \\
\text { Keterangan: } & \\
\text { FC } & =\text { Biaya tetap } \\
\text { VC } & =\text { Biaya variabel per unit } \\
\mathrm{P} & =\text { Penjualan }
\end{aligned}
$$

\section{Payback Period}

Tingkat pengembalian investasi diartikan sebagai jangka waktu kembalinya investasi yang dikeluarkan melalui keuntungan yang diperoleh dari suatu proyek. secara matematis dapat di rumuskan sebagai berikut;

$\mathrm{PBP}=\mathrm{n}+(\mathrm{a}-\mathrm{b}) /(\mathrm{b}-\mathrm{c}) \times 1$ tahun

\section{Keterangan}

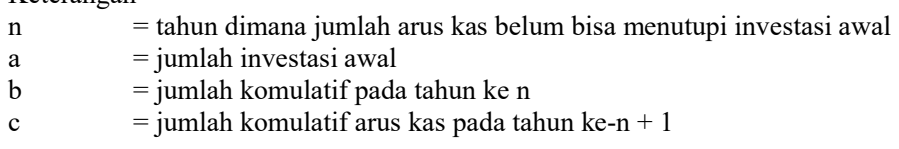

\section{Hasil dan Pembahasan}

3.1. Biaya Produksi dan Penerimaan Usahatani Cabai Keriting.

\subsubsection{Biaya Tetap}

Biaya tetap merupakan biaya yang dikeluarkan untuk memperoleh faktor produksi tetap yang penggunaannya tidak habis dalam satu kali proses produksi. Kelompok Wanita Tani Tunas Muda dalam melakukan usahatani cabai keriting memiliki biaya tetap antara lain biaya pembelian peralatan, dan biaya pajak tanah.

a. Biaya pembelian peralatan.

Biaya pembelian peralatan yang ada di kelompok Wanita Tani sebesar Rp 922,000. Hasil penelitian ini menunjukan bahwa peralatan yang ada di KWT Tunas Muda tidak dihitung nilai Penysutannya, karena peralatan yang ada di Kelompok Wanita Tani pada saat penelitian sudah melewati umur ekonomis, meskipun menggunakan peralatan yang ada, dalam proses produksi. Sehingga diasumsikan bahwa peralatan yang digunakan dalam proses produksi merupakan peralatan yang dibeli baru karena sudah melewati umur ekonomis.

b. Pajak tanah untuk luas lahan 30 are yaitu $\mathrm{Rp} \mathrm{17.000.}$

Jadi total biaya tetap adalah $\mathrm{Rp} 939.000$,

\subsubsection{Biaya Variabel}

Biaya variabel merupakan biaya yang besarnya berubah sejalan dengan perubahan jumlah produksi yang dihasilkan. Biaya variabel untuk usahatani cabai keriting untuk luas lahan 30 are yaitu Rp 3.645.000, uraian lengkap pada Tabel 2. Hasil penelitian menunjukan bahwa bibit dan pupuk tidak dihitung dalam biaya variabel Karena, pupuk merupakan bantuan dari Pemerintah sedangkan bibit yang digunakan dalam proses produksi merupakan bibit yang diambil atau (dipetik) dari musim tanam sebelumnya.

3.1.3 Total biaya Produksi 4.584 .000

Total biaya produksi cabai keriting untuk Luas Lahan 30 are yaitu $\mathrm{Rp}$

\subsubsection{Produksi dan Penerimaan Usahatani cabai keriting.}

Penerimaan adalah jumlah hasil produksi yang diperoleh dalam satu musim tanam yang kemudian dikalikan dengan harga jual per kilogramnya. Penerimaan usahatani cabai keriting untuk satu kali musim tanam dan luas lahan 30 are adalah $720 \mathrm{Kg}$ dengan penerimaan sebesar Rp 14.014.000. untuk lebih jelasnya tentang produksi dan penerimaan cabai keriting untuk satu kali musim tanam dengan luas lahan 30 are dapat dilihat pada Tabel 3.

\section{Tabel 1. Biaya Tetap}

\begin{tabular}{llcccc}
\hline & $\begin{array}{l}\text { Uraian } \\
\text { No }\end{array}$ & Jumlah & $\begin{array}{c}\text { Harga/ } \\
\text { satuan (Rp) }\end{array}$ & $\begin{array}{c}\text { Jumlah } \\
\text { Harga (Rp) }\end{array}$ & Keterangan \\
\hline 1 & Pacul & 6 & 55.000 & 330.000 & Dibeli \\
2 & Ember & 6 & 40.000 & 240.000 & Dibeli \\
3 & Karung & 4 & 5.000 & 20.000 & Dibeli \\
4 & Parang & 4 & 52.000 & 208.000 & Dibeli \\
5 & Tajak & 7 & 17.000 & 119.000 & Dibeli \\
6 & Tali bedeng & 1 & 5.000 & 5.000 & Dibeli \\
7 & Sekop & 2 & --- & --- & Bantuan Pemerintah \\
8 & Penyemprot & 2 & --- & --- & Bantuan Pemerintah \\
9 & Motor air & 1 & --- & --- & Bantuan Pemerintah \\
10 & Selang & 1 & --- & --- & Bantuan Pemerintah \\
\hline
\end{tabular}

Sumber: data primer (diolah)

Tabel 2. Biaya Variabel

\begin{tabular}{lc}
\hline Uraian Biaya & Jumlah (Rp) \\
\hline Komsumsi & 2.037 .000 \\
Biaya sewa transportasi & 688.000 \\
Sewa tenaga kerja & 521.000 \\
Pembelian bensin & 100.000 \\
Pembelian obat-obatan & 299.000 \\
\hline Total & 3.645 .000 \\
\hline Sumber: data primer (diolah) &
\end{tabular}

Tabel.3 Penerimaan Usahatani cabai Keriting

\begin{tabular}{lccc}
\hline Masa panen & Produksi $(\mathrm{Kg})$ & Harga $(\mathrm{Rp})$ & Penerimaan (Rupiah) \\
\hline panen 1 & 40 & 20.000 & 800.000 \\
panen 2 & 87 & 20.000 & 1.740 .000 \\
panen 3 & 131 & 22.000 & 2.882 .000 \\
panen 4 & 164 & 18.000 & 2.952 .000 \\
panen 5 & 105 & 15.000 & 1.575 .000 \\
panen 6 & 70 & 15.000 & 1.050 .000 \\
panen 7 & 50 & 20.000 & 1.000 .000 \\
panen 8 & 35 & 25.000 & 875.000 \\
panen 9 & 21 & 30.000 & 630.000 \\
panen 10 & 17 & 30.000 & 510.000 \\
\hline Jumlah & 720 & & 14.014 .000 \\
\hline \multicolumn{3}{l}{ Sumber: data primer (diolah) }
\end{tabular}

Tabel 3 menjelaskan bahwa produksi dan penerimaan usahatani cabai keriting berbeda - beda setiap masa panennya. Masa panen pertama yaitu sebesar $40 \mathrm{Kg}$. Pemanenan cabai umumnya, soal selang waktu memang sulit dijadikan patokan. Patokan yang umum bagi cabai merah, bahwa usia produktif hanya sampai 6-7 bulan saja. Hasil panen tertinggi pada masa panen keempat dan yang terendah pada hasil panen kesepuluh.

\subsection{Analisis Finansial}

\subsubsection{Laporan Arus Kas}

Laporan arus kas merupakan laporan yang mendefenisikan dana sebagai kas, yang memberikan informasi mengenai pengeluaran dan pemasukan usahatani dalam suatu periode. Laporan arus kas KWT Tunas Muda dapat dilihat pada tabel 4 .

Tabel 4 menggambarkan arus kas, pengeluaran atau biaya pada bulan ke0 yaitu bulan dimana modal awal (investasi awal), sebesar Rp 2.539.000, yang digunakan untuk pembelian sarana dan prasarana KWT Tunas Muda, pembersihan lahan, pengolahan lahan, persemaian dan pembuatan lubang tanam. Pada bulan 1-7 yaitu pengeluaran untuk penanaman, pembersihan gulma pemupukan lanjutan sampai dengan panen dan pasca panen cabai keriting. Arus kas masuk yang teridiri dari Keuntungan bersih (Net Profit) ditambah dengan depresiasi, Cash in mulai terbentuk pada bulan keempat disebabkan pemanenan pertama dimulai pada tersebut, da berakhir pada bulan ketujuh sehingga arus kas masuk pada usahatani Cabai Keriting di KWT Tunas Muda merupakan hasil penjualan cabai keriting sebesar Rp 14.014.000, dan depresiasi tidak dihitung karena umumnya alat yang digunakan merupakan alat yang umur ekonomisnya sudah habis karena sudah berusia lebih dari 10 tahun periode 2018 .

\subsubsection{R/C Rasio}

$\mathrm{R} / \mathrm{C}$ rasio merupakan alat analisis yang digunakan untuk melihat keuntungan relatif usahatani cabai keriting. R/C Rasio untuk usahatani cabai keriting dengan Luas lahan 30 are dapat di lihat pada tabel berikut:

Berdasarkan Tabel $5 \mathrm{R} / \mathrm{C}$ ratio pada usahatani cabai keriting dengan luas lahan 30 are di setiap masa penerimaan/ panennya dikategorikan tidak layak di laksanakan karena tidak memenuhi kriteria R/C Ratio, jika layak maka usahatan cabai keriting dengan luas lahan 30 are harus $>1$. Sedangkan perhitungan $R / C$ selama satu musim tanam dengan 10 kali masa panen adalah sebagai berikut: 


$$
\begin{aligned}
\mathrm{R} / \mathrm{C} \text { rasio } & =\frac{\mathrm{Rp} 14.014 .000}{4.584 .000} \\
& =3,06
\end{aligned}
$$

Dari hasil perhitungan diatas nilai $\mathrm{R} / \mathrm{C}$ rasio sebesar 3,06. Dan dapa dikatakan bahwa jika pengeluaran dari KWT sebesar Rp. 1 ,- maka, akan mendapatkan keuntungan sebesar Rp. 3,06. Jadi peran atau pengorbanan wanita tani dalam usahatani cabai Keriting di KWT Tunas Muda untuk tingkat keuntungan relatif adalah 3,06. Sehingga dikatakan bahwa usahatani cabai keriting layak untuk dilaksanakan.

Tabel 4. Laporan Arus Kas KWT Tunas Muda Arus Kas Usahatani Cabai Keriting

"KWT Tunas Muda" Periode 2018

\begin{tabular}{lccc}
\hline Bulan & Cash Out $(\mathrm{Rp})$ & Cash In (Rp) & Net Cash Flow \\
\hline 0 & 2.539 .000 & & -2.539 .000 \\
1 & 447.000 & & -447.000 \\
2 & 71.000 & & -71.000 \\
3 & 68.000 & & -68.000 \\
4 & 565.000 & 5.422 .000 & 4.857 .000 \\
5 & 294.000 & 5.577 .000 & 5.283 .000 \\
6 & 198.000 & 2.505 .000 & 2.307 .000 \\
7 & 402.000 & 510.000 & 108.000 \\
\hline Jumlah & 4.584 .000 & 14.014 .000 & 9.430 .000 \\
\hline Rata-Rata & 654.857 & 2.002 .000 & 1.347 .143 \\
\hline
\end{tabular}

Sumber: data primer (diolah)

Tabel 5. R/C rasio

\begin{tabular}{lcll}
\hline Masa Panen & TR & Akumulasi TC & R/C Rasio \\
\hline 1 & 800.000 & 3.408 .000 & 0,23 \\
2 & 1.740 .000 & 3.524 .000 & 0,49 \\
3 & 2.882 .000 & 3.690 .000 & 0,78 \\
4 & 2.952 .000 & 3.760 .000 & 0,79 \\
5 & 1.575 .000 & 3.811 .000 & 0,41 \\
6 & 1.050 .000 & 3.984 .000 & 0,26 \\
7 & 1.000 .000 & 4.057 .000 & 0,25 \\
8 & 875.000 & 4.105 .000 & 0,21 \\
9 & 630.000 & 4.182 .000 & 0,15 \\
10 & 510.000 & 4.584 .000 & 0,11 \\
\hline Total & 14.014 .000 & & 3,06 \\
\hline
\end{tabular}

Sumber: data primer di olah

\subsubsection{Net Present Value}

Istilah Net Present Value sering diterjemahkan sebagai nilai bersih sekarang. Perhitungan NPV dalam suatu penilaian investasi merupakan cara yang praktis untuk mengetahui apakah proyek menguntungkan atau tidak. Perhitungan Net Present Value untuk usahatani cabai keriting yaitu perhitungan dilakukan dengan waktu yang dipakai yaitu bulan. Bulan dimana cabai keriting mulai ditanam sampai proses pemanen selesai. Usahatani cabai keriting yang dibudiyakan di KWT Tunas Muda umum berumur 7 bulan, dan panen pertama yaitu pada bulan ke-4.

Tingakat bunga yang dipakai merupakan tingkat bunga Bank Indonesia. Menurut Mishkin (2008) Suku Bunga adalah biaya pinjaman atau harga yang dibayarkan untuk dana pinjaman yang dinyatakan dalam presentase. BI rate adalah suku bunga Instrumen sinyaling Bank Indonesia yang ditetapkan pada RDG (Rapat Dewan Gubernur) dalam bentuk triwulan. Sehingga dalam hasil perhitungan ini, tingkat bunga yang dipakai adalah tingkat bunga Bank BI yaitu pada periode bulanan, sebesar 4,5\% yang berlaku pada 2018 .

Perhitungan NPV pada usahatani cabai Keriting dengan nilai waktu adalah bulan, didasarkan pada penelitian terdahulu dengan judul "Studi Kelayakan Usahatani Cabai Merah di Desa Kacangan Kecamatan Ngunut Kabupaten Tulungagung. hasil penelitian tersebut menunjukkan bahwa nilai NPV dari usahatani cabai monokultur seluas $1 \mathrm{Ha}$ adalah $>0$ atau bernilai positif.

Berdasarkan hasil penelitiannya maka perhitungan nilai bersih sekarang (NPV) pada usahatani cabai keriting dengan luas lahan 30 are, dapat dilihat pada tabel 6.

Berdasarkan hasil pada Tabel 6 nilai bersih sekarang present value sebesar Rp 6.894.278 sehingga dapat dikatakan bahwa nilai bersih sekarang untuk usahatani cabai keriting $>0$ dan layak untuk dilaksanakan. Dengan demikian bahwa kontribusi wanita tani dapat memberikan keuntungan bersih sekarang bagi KWT Tunas Muda sebesar Rp 6.526.015, dengan alasan bahwa kelompok wanita tani Tunas Muda dalam melakukan usahatani dengan luas lahan 30 are memiliki manajemen waktu yang baik, dan pemanfaatan nilai uang dimasa yang akan datang dengan baik, sehingga pembangunan pertanian dimasa yang akan datang tidak terlepas dari wanita tani meski peran wanita terkesan dikesampingkan, namun upaya mewujudkan pembangunan pertanian harus melibatkan peran wanita tani (Pujiharto dan Watermin, 2008).
Tabel 6. Net Present Value

\begin{tabular}{cccc}
\hline Bulan & $\begin{array}{c}\text { Net Cash Flow } \\
(\mathrm{Rp})\end{array}$ & $\begin{array}{c}\text { Tingkat Bunga Bank BI. } \\
(4.25 \%)\end{array}$ & $\begin{array}{c}\text { Present } \\
\text { Value }\end{array}$ \\
\hline 0 & -2.539 .000 & 1,00 & -2.539 .000 \\
1 & -447.000 & 0,96 & -428.777 \\
2 & -71.000 & 0,92 & -65.329 \\
3 & -68.000 & 0,88 & -60.018 \\
4 & 4.857 .000 & 0,85 & 4.112 .102 \\
5 & 5.283 .000 & 0,81 & 4.290 .425 \\
6 & 2.307 .000 & 0,78 & 1.797 .178 \\
7 & 108.000 & 0,75 & 80.703 \\
\hline Net Present Value & & 6.894 .278 \\
Sumber: data primer (diolah) & &
\end{tabular}

\subsubsection{Internal Rate Of Return}

Internal Rate Of Return (IRR) merupakan metode perhitungan investasi dengan menghitung tingkat bunga, yang menyamakan nilai sekarang investasi dengan nilai penerimaan- penerimaan kas bersih dimasa yang datang. Perhitungan Nilai IRR untuk usahatani cabai keriting dengan luas lahan 30 are dengan berpatokan pada tingkat suku bunga Kredit Usaha Rakyat (KUR) sebesar $4,25 \%$ yaitu sebesar 30 persen, yang berarti bahwa nilai IRR lebih besar dari tingkat suku bunga bank, sehingga usahatani cabai keriting layak untuk dilaksanakan. Dengan demikian bahwa peran wanita dalam melakukan usahatani cabai keritng dapat memberikan nilai IRR sebesar 30 persen atau nilai kas bersih dimasa-masa yang akan datang, kontribusi wanita tani dalam Kelompok Wanita Tani sebesar 30 pesren.

\subsubsection{Break Event Point}

Break Event Point atau titik impas yang penerimaannya sama dengan pengeluaran, untuk penerimaan sebesar Rp 14.014.000, dan pengeluaran Rp 4.584.000 dan keuntungan yang diterima adalah $\mathrm{Rp} 9.430 .000$, dengan kisaran harga Rp 15.000 sampai dengan Rp 30.000/Kg yang diterima KWT Tunas Muda Sedangkan Perhitungan BEP atas dasar penjualan dalam unit sebesar $213 \mathrm{Kg}$, dan BEP atas dasar penjualan dalam rupiah sebesar Rp 4.584.000.

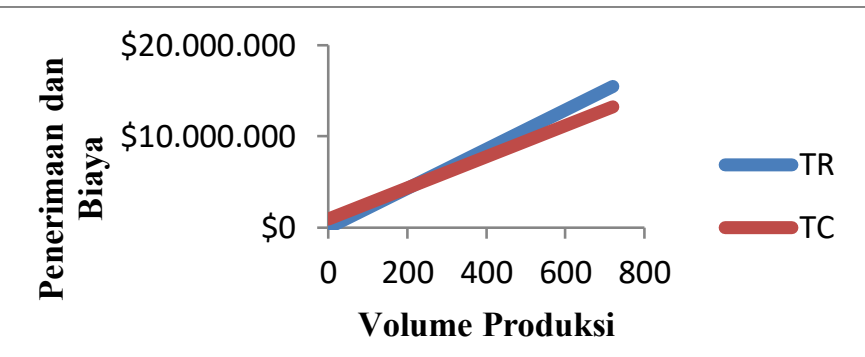

Gambar 1. Kurva Break Event Point

Dari kurva pada gambar 1 dapat dijelaskan bahwa, perpotongan total biaya dan total penerimaan usahatani cabai keriting yaitu pada volume produksi $213 \mathrm{Kg}$, pada penerimaan dan biaya sebesar $\mathrm{Rp} 4.584 .000$ sehingga peran wanita dalam melakukan usahatani cabai keriting dengan luas lahan 30 are mendapatkan titik impas pada volume produksi $213 \mathrm{Kg}$ dan harga rata-rata penjualan cabai keriting per-kg sebesar Rp 21.500;

\subsubsection{Payback Period}

Payback Period atau Tingkat pengembalian investasi diartikan sebagai jangka waktu kembalinya investasi yang dikeluarkan melalui keuntungan yang diperoleh dari suatu proyek atau Jangka waktu yang dibutuhkan untuk mengembalikan nilai investasi melalui penerimaan-penerimaan yang dihasilkan oleh proyek investasi tersebut.

Tabel 7 menjelaskan bahwa tingkat pengembalian biaya yang dikeluarkan yaitu pada bulan ke-3, 21 hari dan dalam perhitung masa panen, pada masa panen ketiga dan ke empat. Sehingga dapat dikatakan bahwa tingkat pengembalian usahatani lebih cepat dan layak dilaksanakan dengan alasan bahwa tingkat pengembalian biaya pada masa panen bulan pertama yaitu pada bulan ke-3, bulan 21 hari. Dengan demikian bahwa peran wanita dalam melakukan usahatani cabai keriting di Kelompok Wanita tani Tunas Muda mendapatkan tingkat pengembalian lebih awal atau pada penerimaan bulan pertama. Asumsinya bahwa wanita dalam melakukan usahatani cabai keriting, dari masa pembersihan lahan sampai pasca panen melakukannya dengan baik dan manajemen waktu yang tepat.

Berdasarkan hasil perhitungan secara finansial usahatani cabai keriting pada Kelompok Wanita Tani layak dilaksanakan karena telah memenuhi kriteria kelayakan secara finansial dengan demikian bahwa peran wanita dalam usahatani cabai keriting, menggambarkan bahwa wanita mampu berproduksi seperti halnya laki-laki. Manajemen waktu yang dilakukan oleh wanita tani patut dihargai, karena memiliki peran ganda dalam rumah tangga (Elizabeth, 2008). Sedangkan Faktor pembatas produktivitas yang berkaitan dengan gender antara lain adalah status sosial, hambatan memperoleh pekerjaan, status pekerjaan dan beban simultan wanita dibandingkan dengan peran sekuensial pada kaum pria, (Suradisastra, 1998). 
Perhitungan Payback Period dengan penerimaan yang dikumulatif dapat dilihat pada tabel 7:

Tabel 7. Nilai Payback Period

\begin{tabular}{cccc}
\hline Bulan & $\begin{array}{c}\text { Net Cash Flow } \\
(\mathrm{Rp})\end{array}$ & $\begin{array}{c}\text { NCF } \\
\text { Kumulatif }\end{array}$ & $\begin{array}{c}\text { Payback } \\
\text { Period }\end{array}$ \\
\hline 0 & $-2,539,000$ & $-2,539,000$ & \\
1 & $-447,000$ & $-2,986,000$ & \\
2 & $-71,000$ & $-3,057,000$ & \\
3 & $-68,000$ & $-3,125,000$ & \\
4 & $4,857,000$ & $1,732,000$ & 3.64 \\
5 & $5,283,000$ & $7,015,000$ & \\
6 & $2,307,000$ & $9,322,000$ & \\
7 & 108,000 & $9,430,000$ & \\
\hline
\end{tabular}

Sumber : data primer (diolah)

\section{Simpulan}

Hasil penelitian yang bertujuan untuk mengetahui gambaran umum usahatani cabai keriting dan kelayakan Finansial Usahatani Cabai Keriting di Desa Lawalutolus Kecamatan Tasifeto Barat (Studi Kasus Kelompok Wanita Tani Tunas Muda) menujukan bahwa: (1). Usahatani cabai keriting yang dilakukan oleh KWT Tunas Muda memiliki manajemen waktu yang baik dalam melalukan usahatani dari awal persiapan sampai dengan panen cabai keriting dan memiliki manajemen keuangan yang baik, meskipun masih sangat sederhana. (2). Analisis kelayakan secara finansial bahwa usahatani cabai keriting dengan luas lahan 30 are memiliki nilai positif dan layak untuk dilaksanakan.

\section{Pustaka}

Badan Pusat Statistik .2019. Indonesia Dalam Angka 2016 - 2018. BPS. Jakarta Badan Pusat Statistik Kab. Belu. 2019.Kabupaten Belu Dalam Angka 2019. BPS. Atambua.

Badan Pusat Statistik Provinsi NTT. 2019. Provinsi Nusa Tenggara Timur Dalam Angka 2018.BPS. Kupang

Cahyono, B. 2003. Cabai Rawit Teknik Budidaya Dan Analisis Usaha Tani. Kanisius. Yogjakarta.

Mishkin. 2008. Ekonomi Uang, Perbankan dan pasar keuangan. Salemba Empat : Jakarta.

Pujiharto, Watemin. 2008. Kajian Partisipasi Wanita Tani dalam Pengelolaan Tanaman Padi Sawah Terpadu di Kecamatan Bukateja Kabupaten Purbalingga. AGRITECH, VOL. X NO. 2 DES. 2008 : $82-95$.

Riyanto, B. 1997. Dasar-dasar Pembelanjaan Perusahaan, Edisi 4. BPFE, Yogyakarta.

Elizabeth, R. 2008. Peran Ganda Wanita Tani dalam Mencapai Ketahanan Pangan Rumah Tangga di Pedesaan. Iptek Tanaman Pangan Vol. 3 No. 1 tahun $2008: 59-68$.

Soekartawi, AS, JL Dillon, JB Hardaker .2011. Ilmu Usaha Tani dan Penelitian Untuk Pengembangan Pertanian. Kecil. Universitas Indonesia Press. Jakarta.

Suradisastra.K. 1998. Perspektif keterlibatan Wanita di Sektor Pertanian. Forum Peneliti Agr Ekonomi. VOL. 16 NO. 2 Desember 1998 : 1 - 9. 